This item was submitted to Loughborough's Institutional Repository by the author and is made available under the following Creative Commons Licence conditions.

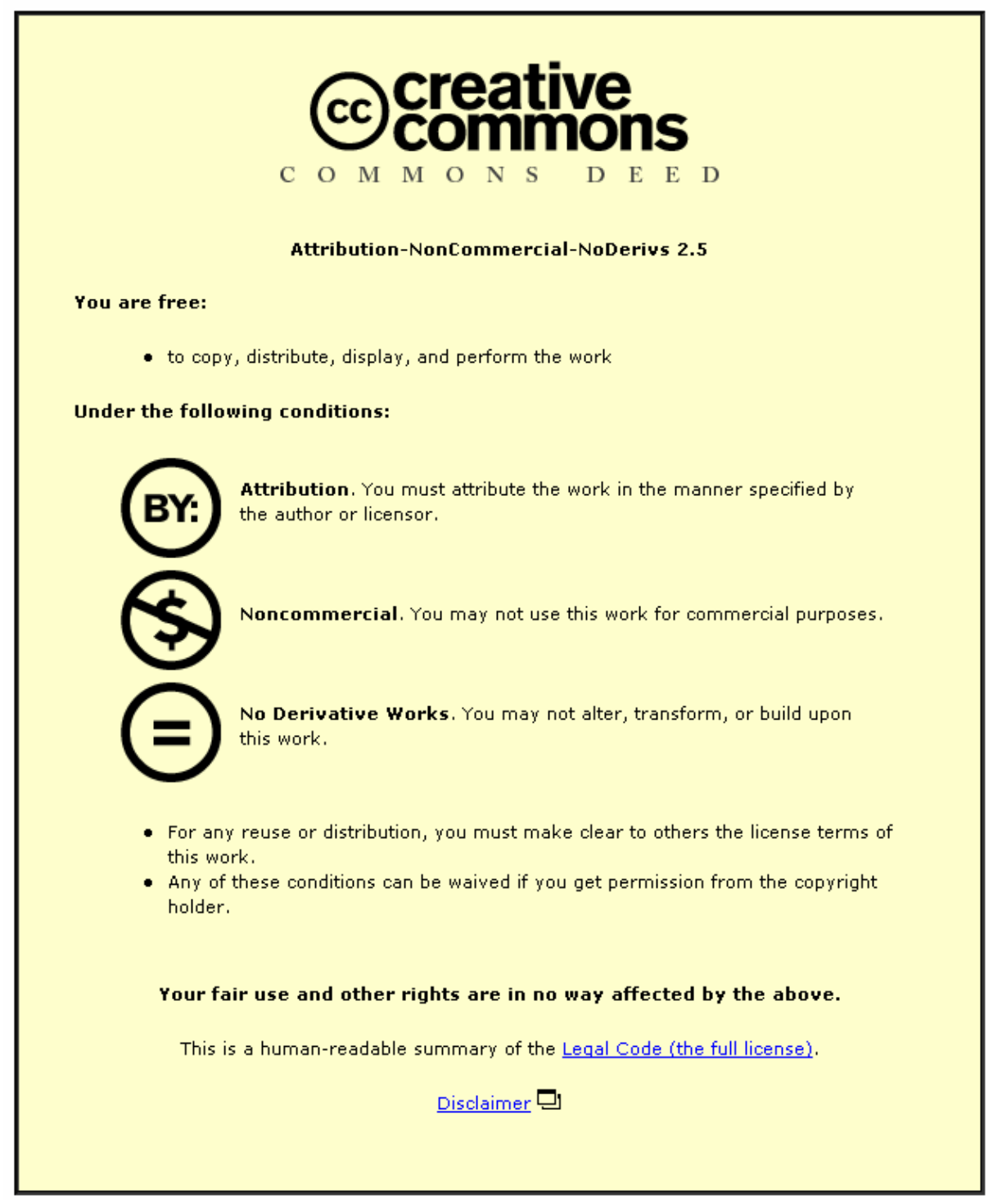

For the full text of this licence, please go to: http://creativecommons.org/licenses/by-nc-nd/2.5/ 


\title{
Simplified Laboratory Assessment of Subgrade Performance Parameters for the Mechanistic Design of Pavement Foundations
}

\author{
$(5485$ words $+(8 \times 250))=7485$ Total
}

Matthew, W, Frost, Department of Civil and Building Engineering, Loughborough University, Loughborough, Leicestershire, LE11 3TU, UK, +44 (0)1509 228306, Fax +44 (0)1509 223981, m.w.frost@lboro.ac.uk. (corresponding author)

J, Paul, Edwards, Scott Wilson Pavement Engineering, Nottingham Science and Technology Park, University Boulevard, Nottingham, UK, NG7 2QP, UK, +44 (0)115 9229098, Fax +44 (0)115 9431302,paul.edwards@scottwilson.com

Paul, R, Fleming, Department of Civil and Building Engineering, Loughborough University, Loughborough, Leicestershire, LE11 3TU, UK, +44 (0)1509 222616, Fax +44 (0)1509 223981 , p.r.fleming@lboro.ac.uk

Stuart, J, Arnold, Scott Wilson Pavement Engineering, Nottingham Science and Technology Park, University Boulevard, Nottingham, UK, NG7 2QP, UK, +44 (0)115 9229098, Fax +44 (0)115 9431302, stuart.arnold@scottwilson.com

\begin{abstract}
With the increasing agenda for sustainability, the UK is attempting to move away from the empirical design of pavement foundations to develop a performance specification approach to facilitate analytical design. For analytical design the measurement of the subgrade performance parameters of resilient modulus and resistance to permanent deformation are required. These parameters ideally need to be assessed concurrently under loading and environmental conditions similar to those the materials will experience in the field. To date, measurement of these parameters is largely confined to research laboratories using cyclic triaxial testing with advanced on sample strain measurement. This apparatus is considered too complicated for routine commercial use, hence this potentially limits the implementation of laboratory performance evaluation for routine pavement foundation design.

A previous program of cyclic triaxial testing on clay subgrades indicated a series of useful correlations between strength and permanent deformation behavior (via a threshold stress), and material resilient modulus at this threshold. This paper reviews the previous work and utilizing these correlations presents data from tests on three different clay materials performed to develop simplified equipment and procedures for the routine measurement of the required design parameters. It is shown that simple pseudo-static tests can measure a subgrade modulus for a simplified performance based design. It re-evaluates the previous data (in the light of the recent work) to show a boundary correlation that may allow a shear strength based parameter to control (in design) the onset of permanent deformation, and details how long-term subgrade water content changes can be accommodated.
\end{abstract}

\section{INTRODUCTION}

Currently UK pavement foundation design is based on a (prescriptive) method specification using design data based on the CBR test (or tests correlated to it). This approach has been used for many years and is based on satisfactory observed past performance of selected materials constructed to a prescribed method specification. The completed foundation is assumed to have an adequate performance and is not thereafter accounted for the in upper pavement design. However such a prescriptive approach limits the use of marginal or recycled materials, and does not facilitate best use of the good performance of the foundation or the subgrade. With the increasing agenda for sustainable construction there is a move away from method specifications to 'performance-based' specifications based on 'fit for purpose' (1). This also enables better integration with mechanistic design methods.

A key element of performance-based specifications is the ability to measure the subgrade performance parameters of resilient modulus and resistance to permanent deformation for both mechanistic design and compliance during construction. These two parameters ideally need to be assessed initially in the laboratory under loading and environmental conditions similar to those that they will experience in the field. To-date accurate measurement of these parameters at appropriate field 
sustained stress conditions has been largely confined to research laboratories using sophisticated cyclic triaxial testing with on sample strain measurement, measuring at the small strain /very small strain boundary. This type of testing is considered too complicated for routine commercial use, and hence this potentially limits the implementation of laboratory performance evaluation for pavement foundation design.

A previous program of cyclic triaxial testing on clay subgrades undertaken by the authors (2), indicated a series of useful correlations: between strength and the onset of excessive permanent deformation (a point termed the threshold stress); and this threshold stress with the material resilient behavior reading on the asymptote. It was considered that these correlations could potentially be utilized for developing a simplified method for pavement foundation design, and are attractive as this only requires a simplified method of laboratory measurement. This paper thus discusses the elements required for a road foundation performance based specification, it briefly presents the required performance behavior of fine grained materials and then reviews the correlations previously developed from cyclic triaxial testing. The results of more recent cyclic testing together with data from pseudo static tests undertaken to develop the simplified method and testing apparatus are included and compared to the previous work. Concluding on these results the key areas are highlighted where the current lack of understanding precludes the implementation of a fully analytical design method and hence a true performance based specification. Future research work is suggested to address these challenges.

\section{A PERFORMANCE SPECIFICATION FOR PAVEMENT FOUNDATIONS}

For a pavement foundation to perform adequately it must fulfill the following three functions:

- It must support a limited number of vehicles during the construction of overlying layers. The foundation must not deform under trafficking to reduce the effectiveness of the compacted structure and it must dissipate the high stresses applied by wheels to a low level to ensure that the subgrade beneath does not sustain significant permanent deformation (rutting).

- It must provide an adequate reaction for the placing and compaction of the overlying layers.

- It must provide adequate support to the overlying layers when the road pavement is in-service, and distribute the stresses transmitted through the bound layers, and applied to the subgrade, to a sufficiently low level to maintain the integrity of the whole pavement.

In addition, the materials used must possess stability and durability in the long-term. The first two requirements are for (short-term) construction conditions whereby relatively few passes of high applied stress occur. Condition three is a long-term design requirement to resist many millions of stress applications (of lower magnitude) over many years. However, during this time the foundation materials may alter behavior due to loading history and drainage/environmental effects.

To fulfill these requirements the pavement foundation materials (themselves and in their combined layer form) must achieve adequate levels of resilient modulus and resistance to permanent deformation. Therefore to assess the material performance, there must exist:

1. an ability to measure the performance parameters of the subgrade in the laboratory for both the short-term construction condition and the expected long-term in-service condition,

2. a method of predicting and modeling the environmental changes in the pavement over the longterm,

3. a means of incorporating the measured parameters into the design process, and

4. an ability to measure the same parameters for the subgrade and pavement foundation layers in the field to assess compliance and provide assurance of the quality of the as built product.

Requirements 1, 3 and 4 have been addressed elsewhere (1, 2 and 3). However, item 2 requires an understanding of the changes in suction and hence water content, (both during construction and longer-term) due to subgrade mineralogy, water table depth and drainage effects, these areas clearly require significant further research. However, it can clearly be seen that laboratory assessment of subgrade performance presents a crucial element in the satisfactory development and application of performance based specifications and for implementation of mechanistic-analytical design.

\section{THE BEHAVIOR OF FINE-GRAINED SOILS UNDER REPEATED LOADING}

The resilient elastic modulus of cohesive, fine-grained soils decreases non-linearly with increasing applied stress, when other factors (subsequently described) are kept constant (Figure 1). 
Materials exhibiting high suctions (negative pore water pressures) have been shown to have higher resilient moduli, indicating modulus to be a function of three stress variables: the confining stress, the axial stress and the matrix suction of the materials. Significantly no changes in resilient response with variations of loading frequency have been observed. Additionally, for a constant confining stress at high deviator stresses the modulus tends to a constant value termed the resilient modulus (stiffness) asymptote (2). Additionally it has to be considered that during construction the soils will be subject to a wide variety of stress applications during placement of/as fill materials and during compaction, principally due to changes in deviatoric stress level, this means the stress paths that the soils follow are very complex. Thus the subgrade resilient response will change during construction through to the inservice loading conditions.

For permanent deformation behavior, the rate of accumulation of permanent strain increases as the cyclic stress level/magnitude increases (Figure 1). This leads to a deviator stress level, termed the 'threshold stress' ( $\mathrm{q}_{\text {threshold }}$ ), above which the rate of accumulation of deformation increases significantly. This response has been shown to be related to the material's stress history and water content, and thus its undrained shear strength. Whilst material behavior is reasonably well understood for the resilient strains when subject to the complex stress paths referred to above, the permanent deformation response is currently less well defined. Therefore, to restrict the accumulation of excessive permanent deformation the use of the relationship between applied shear stress (q) and the shear strength of the soil (i.e. stress ratio, $\mathrm{q} / \mathrm{q}_{\max }$ ) currently appears a satisfactory criterion.

The concept of a limiting value of $\mathrm{q} / \mathrm{q}_{\max }$ (i.e. $\mathrm{q}_{\text {threshold }} / \mathrm{q}_{\max }$ ) above which plastic deformation increases relatively rapidly has been suggested before, (4) proposed that for design purposes this threshold should be taken at a deviator stress equivalent to $50 \%$ of the soil's measured suction. In contrast it has also been suggested that the threshold stress occurs at approximately the deviator stress required to generate $1 \%$ permanent strain in a sample following 1000 applications of stress at progressively increasing levels of deviator stress application (Figure 1). In the UK 1000 cycles is the estimated likely maximum number of construction traffic vehicle cycles, and this is used in designing the foundation.

\section{THE PROBLEMS OF ROUTINE MEASUREMENT OF PERFORMANCE PARAMETERS}

The complex nature of the loading within a pavement and the resultant material behavior means that advanced testing using cyclic triaxial testing or hollow cylinder apparatus (with appropriate on sample strain measurement) to replicate field loading, and the rotation of principle stresses, is ideally required. However this is currently limited to research laboratories, whereby the full material behavior is often most useful. A more pragmatic approach to obtaining performance data is perhaps required for routine application, and for simple mechanistic design. The more complex laboratory apparatus have their own limitations, often related to sample set up and size, particle size or simulation of field stress conditions. However, with a fuller understanding of the design requirements and material behavior it is suggested that simplified testing can be developed that can be quickly, simply and routinely used.

\section{TECHNIQUES AVAILABLE FOR ROUTINE / SIMPLIFIED PERFORMANCE EVALUATION}

Any simplified approach to obtaining performance data must accommodate both resilient and permanent deformation measurement. There are two approaches to this, firstly, to assess them directly which means ideally the resilient and permanent strains should be assessed concurrently, indicating repeated load type tests are required. Secondly, by using an approach where one or other of the parameters can be indirectly assessed using appropriate correlations and thus utilizing more simple techniques. Both these approaches are currently being investigated by the authors. The first approach is being investigated via the development of a variably confined Springbox which has primarily been developed for granular materials but has shown potential for testing fine grained materials and is reported elsewhere (5). The second is via a simplified measurement of both resilient modulus and permanent deformation in the laboratory using correlations, (the development of this latter approach is reported herein). 


\section{THE BASIS OF A SIMPLIFIED LABORATORY MEASUREMENT OF SUBGRADE PERFORMANCE AND ITS APPLICATION IN DESIGN}

Previous research by the authors incorporated an extensive series of cyclic triaxial tests with on sample strain measurement on a range of typical UK Clay subgrades such as Oxford and London Clay, and a silty Clay, (Mercia Mudstone) (e.g. clays of low, medium and high plasticity, see 2). Within these tests stress and strain data were collected through out, which was subsequently analyzed to evaluate values of threshold stress and asymptotic modulus. Two approaches were used to determine threshold stress, by defining the threshold stress as either the deviator stress at which $1 \%$ permanent strain was reached or the deviator stress at the point of maximum curvature in the curves of permanent strain against deviator stress. Threshold stresses defined in these two ways are plotted against the respective samples' undrained shear strength in Figure 2 (reproduced from reference 2) and the lines of best fit give similar coefficients of correlation. Figure 2 also includes a correlation to illustrate the definition of the threshold stress as being equal to $0.5 \mathrm{q}_{\max }$, i.e. $50 \%$ of the deviator stress at failure i.e. threshold stress $=\mathrm{C}_{\mathrm{u}}$ (the undrained shear strength of the sample). This gives a remarkably similar correlation to that for the two strain dependant approaches.

Figure 3 (reproduced from reference 2) shows the resilient moduli at a deviator stress of $0.5 \mathrm{q}_{\max }$ compared to the 'asymptotic (resilient) modulus' values determined from graphs of resilient modulus against deviator stress for a variety of clay types (from high to low plasticity and silty clays), in both their disturbed and remolded states. A linear relationship with a strong correlation over a broad range of sample moduli is evident. This suggests that when a sample has reached the threshold stress (i.e. the point at which the development of permanent strain is becoming unstable), the resilient modulus is at or approaching a constant (lower bound) value at which the resilient strain is directly proportional to applied stress, hence giving the resilient modulus asymptote described earlier. This thus demonstrates that the magnitude of the resilient response of the clay subgrade should be greater than the resilient modulus asymptote value, if the deviator stresses applied are less than the 'threshold' value. This can be controlled by adequate thickness of the foundation layers above to dissipate the applied stresses.

If the threshold stress can be derived more simply than from complex cyclic testing, i.e. estimated as a proportion of $\mathrm{q}_{\max }$ then only the asymptotic resilient modulus and a stress dependency variable for the clay subgrade needs to be measured for use in a mechanistic pavement design. Such a design then only has to consider the subgrade permanent deformation as a function of strength and resilient modulus - based on limiting the applied deviator stresses through the composite foundation structure to the subgrade. It is assumed therein however that the over lying foundation materials themselves have sufficient strength to avoid internal permanent deformation.

The threshold stress relationships shown in Figures 2 and 3 are thus suggested as a potential way forward for design. If the undrained strength of clay subgrade samples can be accurately measured, this could indirectly indicate the limit of allowable applied subgrade deviator stress via the threshold stress/shear strength relationship proposed. This threshold stress limit can then be applied in design for the 'worst case' construction condition. It is also suggested that resilient modulus (and stress dependency) could possibly be assessed more simply within a standard triaxial cell using monotonic loading and unloading (i.e. pseudo static loading), as resilient modulus in general is not significantly load rate or stress history dependent. Alternatively, a single value of resilient modulus measured at threshold stress (i.e. the 'asymptotic modulus') could be appropriate for short-term construction design. These subgrade data can be coupled with resilient modulus data for the overlying (granular) foundation materials and using simple linear elastic analysis the required thickness of granular material can then be derived to meet the subgrade threshold stress requirement.

\section{DEVELOPMENT AND EVALUATION OF THE SIMPLIFIED APROACH}

To further develop this simple approach a series of repeated load triaxial testing with on-sample strain measurement has been performed to evaluate the behavior of carefully controlled laboratory manufactured clay samples. Concurrently, a parallel series of pseudo-static triaxial testing in a conventional triaxial cell was performed on samples at similar water contents to assess the simplified resilient modulus measurement method. The current data has then been compared to the data from (2). 


\section{TEST MATERIALS AND METHODOLOGY}

\section{Materials and Sample Preparation Methodology}

Samples of three common UK clay mineral types were evaluated comprising a Mercia Mudstone (MM), Oxford Clay (OC) and English China Clay (EC), their basic engineering properties are presented in Table 1. Samples for triaxial testing were prepared by drying the clays and breaking them down to clod sizes of less than $5 \mathrm{~mm}$, water was then added to achieve the pre-determined water contents and the material allowed to equilibrate for 24 hours. The soil was then compacted in a $102 \mathrm{~mm}$ diameter, $300 \mathrm{~mm}$ long steel mould from which a $102 \mathrm{~mm}$ diameter $204 \mathrm{~mm}$ long sample was taken for testing. Sample states were targeted across a range of water contents based on the soil index properties of Optimum Moisture Content (OMC), Plastic Limit (PL), and Equilibrium Water Content ( $\mathrm{W}_{\mathrm{EQ}}$ ) and a mid point between $\mathrm{OMC}$ and $\mathrm{W}_{\mathrm{EQ}}$ (for sample water contents see Table 1). $\mathrm{W}_{\mathrm{EQ}}$ was determined using the UK conventional method described in (6). Two series of samples were made using both the $4.5 \mathrm{~kg}$ and $2.5 \mathrm{~kg}$ Proctor hand held rammers using 27 blows applied to each of 12 layers - based on factoring up the standard Proctor compaction methodology to a $300 \mathrm{~mm}$ length sample. Initial trials showed the need for each layer to be scarified to achieve a good inter-layer bond.

\section{The Pseudo-Static and Cyclic Triaxial Test Equipment and Procedures}

For the pseudo-static tests a standard $100 \mathrm{~mm}$ diameter monotonic triaxial apparatus was used with standard dial gauges and proving rings for strain and stress determination. A confining stress of $20 \mathrm{kPa}$ and a seating stress of $10 \mathrm{kPa}$ were applied. The cyclic loading comprised 5 pulses of load/unload applied (at a load rate of $5 \mathrm{~mm} / \mathrm{min}$ ) at each cyclic stress increment, starting at $10 \mathrm{kPa}$, and increasing in $10 \mathrm{kPa}$ steps until 5\% permanent strain was sustained. The sample was then monotonically loaded, to failure (defied as the peak deviator stress or that at $20 \%$ strain) to assess the undrained shear strength. Therefore the testing was strain-controlled (i.e. the time to reach the specified the target cyclic stress was material dependent), and was undrained. Area correction using the normal fixed volume assessment was used, the modulus was calculated from the final cycle with inspection of the previous cycle data to check data consistency.

For the cyclic testing a standard $100 \mathrm{~mm}$ diameter repeated load triaxial apparatus was used. Deflections were measured with an axial LVDT and two on sample Hall Effect Transducers fixed over the central $80 \mathrm{~mm}$ length of the specimen. A confining stress of $20 \mathrm{kPa}$ and a seating stress of $10 \mathrm{kPa}$ were again applied and the samples loaded with 1000 cycles of a sinusoidal deviator stress pulse at 2 $\mathrm{Hz}$, starting at a deviator stress of $10 \mathrm{kPa}$, and increasing in $10 \mathrm{kPa}$ steps until $5 \%$ permanent strain was sustained. The sample was then monotonically loaded to failure, again the tests were performed undrained. This test method matched that used in (2).

\section{COMPARISON OF PSEUDO STATIC AND REPEATED LOAD TESTING DATA}

Figure 4 shows the relationship between resilient modulus and deviator stress measured using the pseudo-static testing regime on the samples of Mercia Mudstone. These results were typical of those observed on all the materials tested and show some stress dependency at low applied deviator stress and at higher deviator stress the modulus tends to the resilient modulus asymptote, as previously observed from cyclic testing (2), the results also are seen to cover a range of values that allows acceptable comparison to cyclic tests across a range of resilient modulus values. Figure 5 shows this same data with the results from the concurrent repeated load triaxial testing for the Mercia Mudstone (note the cyclic triaxial data presented use average strain values from the on-sample strain measurement) to show general trends between the data. Figure 5 shows the pseudo static data to be both less sensitive to changes in stress at low applied deviator stress and produce lower values of resilient modulus asymptote at higher deviator stress than the cyclic tests. The cyclic data itself also shows some variability at very low stress which is probably due to initial movement of the on-sample gauges relative to the sample (pins are used for mounting the gauges, which are pushed in to the sample).

These results may also have been influenced partly by sample preparation, the relatively shorter and lighter $2.5 \mathrm{~kg}$ rammer was found to achieve a more even level of compaction throughout the sample than the $4.5 \mathrm{~kg}$ rammer, producing more uniform, well compacted samples. Compaction layer bonding did appear to influence some of the cyclic triaxial tests, particularly those for clays at a water content dry of optimum where samples were see to shear at the layer interface during the tests. 
In the simplified pseudo static tests a deflection gauge was used that measured the whole sample displacement and thus precision and end effects are expected to influence the data, particularly at lower deviator stresses. A similar response was seen from the whole sample gauges in the cyclic tests relative to the on-sample gauges, as expected. However at higher deviator stresses the values from the on-sample and whole sample gauges do converge to give very similar modulus values as the resilient modulus asymptote is approached, and this convergence occurred approximately at the threshold stress.

At low deviator stress on the higher modulus samples (i.e. dry of OMC samples, located to the top right of the figures) in the pseudo static tests it became difficult to measure resilient strain precisely as the data was read manually. This will also have contributed to the lower stress dependency observed at the lower deviator stress levels, and this is significant for the assessment of the long term in-service subgrade modulus behavior.

Figure 6 shows the values of resilient modulus asymptote plotted against the sample water content for both the pseudo static and cyclic testing data. This demonstrates the similarity between the resilient modulus asymptote for the two testing approaches. The lines of best fit show the correlation coefficient from the pseudo static loading to lie slightly below that for the cyclic loading, suggesting it is a conservative approach.

To evaluate the threshold behavior it is important that the shear strength values assessed do not differ significantly between the two loading regimes and are not influenced by the testing. It is known that the permanent deformation response of samples is load rate dependant and hence it is not prudent to try to assess a threshold stress from the pseudo static tests even after several cycles. Additionally, the permanent deformations observed were larger during pseudo static loading than those observed from cyclic loading, and in some cases the 5\% permanent deformation limit was exceeded during this phase of testing. Therefore, it is important that the sample stress history during testing does not influence the undrained shear strength assessment carried out after cycling. However, within this testing as the deviator stresses applied were in general well below $\mathrm{q}_{\max }$, this should not cause any problems.

Figure 7 presents the re-analysis of strength and permanent deformation data from the previous program of tests (referred to above, 2) and the current repeated load triaxial tests. In this analysis the threshold stress is assumed as the deviator stress required to cause $1 \%$ permanent strain and has been normalized to the sample's undrained shear strength and plotted against the sample's undrained shear strength, (hence samples with a normalized strength value of one have a threshold deviator stress equivalent to the undrained shear strength, as suggested from Figure 2). As observed previously there is a large scatter to the threshold data, however, it shows a boundary below which (as a proportion of undrained shear strength) the threshold has not been reached.

Figure 8 shows this boundary for both the previous data and from the more recent tests. The original data shows the boundary to occur at about $0.5 \mathrm{Cu}$, however, for the more recent data the boundary has been significantly lowered to approximately $0.2 \mathrm{Cu}$, however, the resilient response between the two test series is comparable. This drop is in part attributed to the fact that the original data contains samples in a variety of sample states, (undisturbed, remolded, and remolded and wetted), across a range of material types. Secondly a slightly different compaction and sample preparation method was used for the current work as it was hoped more uniform samples would be produced to allow comparison between test methods. As previously described this lead to bonding problems between layers which may have influenced permanent deformation response. A relatively large number of layers were used in compaction, suggesting the samples may have been over compacted.

Additionally some of the samples tested were comparatively very dry and hence produced more brittle samples. However, the clear evidence of a stability boundary is very significant and of potential importance for design.

\section{IMPLICATIONS FOR DESIGN}

The testing above clearly shows that the simpler pseudo static test methodology developed presents a conservative set of resilient modulus data with some evidence of material stress dependency that could be useful for mechanistic pavement foundation design. The reasonable correlation between asymptotic modulus for the pseudo static and cyclic tests appears suitable to derive a single "high deviator stress" 
modulus value for design (i.e. suited to construction conditions) from the simplified method, albeit slightly conservative relative to that which cyclic data suggests.

There are some obvious areas of concern for future implementation of this method. The range of resilient modulus values measured at resilient modulus asymptote (Figure 5) appears narrow relative to the range of the samples' shear strengths. However, the modulus data appear typical of those previously observed on cyclic testing of UK clay subgrade (7). Only when more variable or mixed soils were assessed was a wider range of moduli values measured across a range of water contents. This is attributed to the influence of the change of particle size distribution (from finer grained to coarser grained) dominating the behavior. However, it is the associated behavior of both the clay sample resilient modulus and strength that is significant for design as both play their role in determining the appropriate foundation layer thickness. However, further work is needed in the field to validate this approach.

To develop more confidence in the lower bound threshold limit it is proposed that an additional suite of tests on good quality undisturbed samples should be performed. With more data the boundary could be perhaps better evaluated as a confidence limit (at a certain percentile of the normalized data), similar to the frequency histogram approach that is often used in the analysis of conventional pavement structural evaluation data.

If no change in subgrade state occurs in the long-term the assessment of the long-term condition using the pseudo static data could be reasonably straight forward utilizing the stress dependency observed. The dissipation of traffic stresses through the full pavement greatly reduces the applied subgrade deviator stress to a very low level, and consequently the subgrade modulus will be expected to be well above that used for the short term design condition (at higher applied stress, see Figure 1). As a consequence the construction case (using the asymptotic modulus) is expected to govern the thickness design of the foundation layers above, based on the design assumption that the foundation is trafficked during construction.

However, it is known that in service the subgrade is subject to changes in environmental conditions that lead to changes in water content, internal effective stress state and hence strength and resilient modulus. The prediction of and preparation of an appropriate sample in the long-term state presents a significant research challenge, as the expected changes are a function of stress history, suction, and environmental conditions (drainage, water table level and clay type etc.), all of which may also be influenced during the construction process. The methods that exist to predict a long-term equilibrium water content are considered to be generally unreliable, and lack of space precludes a full consideration of these issues here. Within conventional UK CBR based design to assess the long-term state samples are either soaked for a set time period or reconstituted at a predicted equilibrium water content (6). Typically, the method in reference 6 predicts a water content 1 to $2 \%$ higher than its original water content - for a soil subject to stress relief (i.e. one located at the base of a cutting) - and predicts a similar water content to its original one for a clay subgrade on "at grade" sections or at shallow depth. However assessment of equilibrium for re-molded soils, similar to those found on embankments, presents a problem due to the shearing and substantial changes in stress history the soil has sustained. Additionally mixed soil types are difficult to evaluate using this prediction method as it is based partly upon the soil's plasticity index.

On Figure 5 samples towards the bottom left of the graph are wetter than those above and to the right. The resilient modulus at a low deviator stress of $10 \mathrm{kPa}$ (similar to that expected under an in service pavement) is higher (except for the softest samples) than the resilient modulus at the asymptote for the stiffer (dryer samples), across the range of water contents assessed. Hence, if the modulus at worst case water content, with a low in-service applied stress, is higher than the short term condition (high stress) modulus, then the short-term condition will govern design as expected, and a single asymptotic modulus design value is valid. A design check is thus suggested where by it is required to confirm that the short-term construction condition sample's design modulus (asymptote) is lower than the soil modulus at low applied stress for the worst case long-term water content.

\section{CONCLUSIONS}

The widespread adoption of mechanistic design and performance specifications for pavement foundations is currently limited by the complex nature of laboratory testing to evaluate the required subgrade performance parameters of resilient modulus and resistance to permanent deformation. Any 
test developed for routine commercial use to measure these performance parameters must ideally be simple, quick to perform and relatively inexpensive to adopt.

This recent research has assessed a simplified methodology for obtaining performance related data utilizing pseudo static testing in a conventional triaxial cell to evaluate clay subgrade resilient modulus. The resilient modulus values assessed appear to be comparable but slightly lower than those assessed in more complex cyclic triaxial testing. The resilient modulus data show some stress dependency through the deviator stress range, with the soil modulus tending to an asymptote at deviator stresses similar to those experienced during construction trafficking of the foundation. This suggests the method developed offers a potential simple way forward for introducing laboratory measured pseudo static modulus values into the mechanistic design of pavement foundations.

To control the development of permanent deformation a threshold stress relationship with shear strength has been further developed for clay subgrades, and a lower bound criterion (expressed as a proportion of shear strength, i.e. $0.2 \mathrm{Cu}$ ) is suggested. Combining the resilient modulus behavior observed with this limiting threshold stress criterion leads to a simplified design method based upon simple triaxial testing, however this boundary needs to be further refined.

However, to evaluate the in-service subgrade design resilient modulus at a long-term equilibrium water content needs to be measured/predicted. This currently is seen as a significant challenge due to the complex nature and number of influencing factors affecting the prediction of equilibrium water content. However, the test data indicates that a comparison between the subgrade resilient response at higher deviator stresses typical of construction traffic loading and the subgrade resilient response (at a suitably adjusted water content) at low deviator stress, (typical of in-service traffic loading), may be an appropriate design check. This would ensure that the short term construction condition is indeed the worse case for design as may be expected due to the clay nonlinear resilient behavior. However, it is suggested that further testing on undisturbed soils is required to enhance the test methodology developed in conjunction with field trials to validate the simplified design process.

\section{ACKNOWLEDGEMENT}

The authors are grateful to Birmingham and Nottingham Trent Universities for their collaboration on this work, and to the UK Highways Agency for funding the research. The opinions expressed are those of the authors not the UK Highways Agency.

\section{REFERENCES}

1. Fleming, P.R., Rogers, C.D.F., Thom, N.H., and Frost, M.W. A performance specification for pavement foundations. Proceedings of the Transportation Geotechnics symposium (M.W.Frost ed). Thomas Telford Publications, London, 2003, pp. 161 to 176.

2. Frost, M.W., P.R. Fleming and C.D.F. Rogers. Cyclic Triaxial Tests on Clay Subgrades for Analytical Pavement Design. The Journal of Transportation Engineering. ASCE Vol. 111 , No. 2, pp. $105-115,2004$

3. Fleming, P.R. and C.D.F Rogers. Assessment of Pavement Foundations During Construction. Transportation, Proceedings of the Institution of Civil Engineers. Vol. 111, No. 2, 1995, pp. 105-115.

4. Brown, S.F., and A.R. Dawson. Two Stage Mechanistic Approach to Asphalt Pavement Design. Proceedings 7th International Conference on Asphalt Pavements. Nottingham, UK. 1992, pp. 16-34.

5. Edwards, J.P., and Thom, N.H., and Fleming, P.R. Development of a Simplified Test for Unbound Aggregates and Weak Hydraulically Bound Materials Utilizing the NAT. Proceedings of the 6th International Symposium on Pavements Unbound UNBAR6 (A.Dawson, ed). A.A.Balkema, Rotterdam, The Netherlands, 2004, pp 3 to 11. 
6. Black, W.P.M and N.W. Lister,. The strength of Clay Fill Subgrades: Its Prediction in Relation to Road Performance, Transport and Road Research Laboratory Report LR889, Crowthorne, Berkshire, UK. 1979.

7. Frost M W, The Performance of Pavement Foundations during Construction, $\mathrm{PhD}$ Thesis, Loughborough University, 2000. 
TABLE 1. Basic Material Properties of Laboratory Clay Samples Tested.

Figure 1. Typical Relationship between Resilient Modulus and Permanent Strain both against Deviator Stress of a Clay Subgrade Sample Tested in a Cyclic Triaxial Test.

Figure 2. Relationship between Threshold Stress and Undrained Shear strength from Repeated Load Triaxial Tests, (Reproduced from 2)

Figure 3. Relationship between Resilient Modulus at Threshold Stress and Asymptotic Resilient Modulus, (Reproduced from 2).

Figure 4. Typical Relationship between Resilient Modulus and Deviator Stress Tested Pseudo Statically in a Conventional Triaxial Cell, for Samples of Mercia Mudstone (MM).

Figure 5. Typical Comparison of the Relationship between Resilient Modulus and Deviator Stress for both Pseudo Static and Cyclic Testing on Mercia Mudstone Samples.

Figure 6. Typical Relationship Between Asymptotic Resilient Modulus and Water Content for Samples Tested using the Pseudo Static Testing Regime and Cyclic Triaxial Testing.

Figure 7. Relationship between Normalized Threshold Stress (Deviator Stress at $1 \%$ Strain / Undrained Shear Strength) and Undrained Shear Strength. 
TABLE 1. Material Properties of Laboratory Clay Samples Tested

\begin{tabular}{|c|c|c|c|c|c|c|c|c|}
\hline \multicolumn{2}{|c|}{ Material } & Code & \multicolumn{6}{|c|}{ Mineralogy } \\
\hline \multicolumn{2}{|c|}{$\begin{array}{c}\text { Mercia } \\
\text { Mudstone Clay }\end{array}$} & $\mathrm{MM}$ & \multicolumn{6}{|c|}{ Predominantly illite $(\sim 80 \%)$, with chlorite, smectite and gypsum. } \\
\hline \multicolumn{2}{|c|}{ Oxford Clay } & $\mathrm{OC}$ & \multicolumn{6}{|c|}{$\begin{array}{l}\text { Predominantly illite, and quartz, with some kaolinite, chlorite, } \\
\text { feldspar and lesser amounts of gypsum, pyrite and organics. }\end{array}$} \\
\hline \multicolumn{2}{|c|}{$\begin{array}{l}\text { English China } \\
\text { Clay }\end{array}$} & \multicolumn{3}{|l|}{$\mathrm{EC}$} & \multicolumn{4}{|c|}{ Predominantly kaolinite. } \\
\hline Material & $\begin{array}{l}\text { MDD } \\
(2.5 \mathrm{~kg})\end{array}$ & $\begin{array}{l}\mathrm{OMC} \\
(2.5 \mathrm{~kg})\end{array}$ & $\begin{array}{l}\mathrm{MDD} \\
(4.5 \mathrm{~kg})\end{array}$ & $\begin{array}{l}\mathrm{OMC} \\
(4.5 \mathrm{~kg})\end{array}$ & $\mathrm{W}_{\mathrm{EQ}}$ & PI & PL & LL \\
\hline MM & 1.81 & 16.5 & 1.87 & 16.0 & 16 & 20 & 16 & 36 \\
\hline OC & 1.48 & 17 & 1.57 & 21.5 & 32 & 23 & 32 & 55 \\
\hline EC & 1.46 & 23 & 1.63 & 18.0 & 31 & 22.5 & 32 & 55.5 \\
\hline
\end{tabular}

$\mathrm{MDD}=$ Maximum Dry Density $\left(\mathrm{Mg} / \mathrm{m}^{3}\right)$

OMC = Optimum Water Content $(\%)$

$\mathrm{W}_{\mathrm{EQ}}=$ Equilibrium water Content $(\%)$

$\mathrm{PI}=$ Plasticity Index $(\%)$

$\mathrm{PL}=$ Plastic Limit (\%)

$\mathrm{LL}=$ Liquid Limit $(\%)$

Standard 2.5Kg Proctor and 4.5Kg "Heavy" modified Proctor compaction methods were used. 
Figure 1. Typical Relationship between Resilient Modulus and Permanent Strain both against Deviator Stress of a Clay Subgrade Sample Tested in a Cyclic Triaxial Test (1000 cycles at each stress increment).

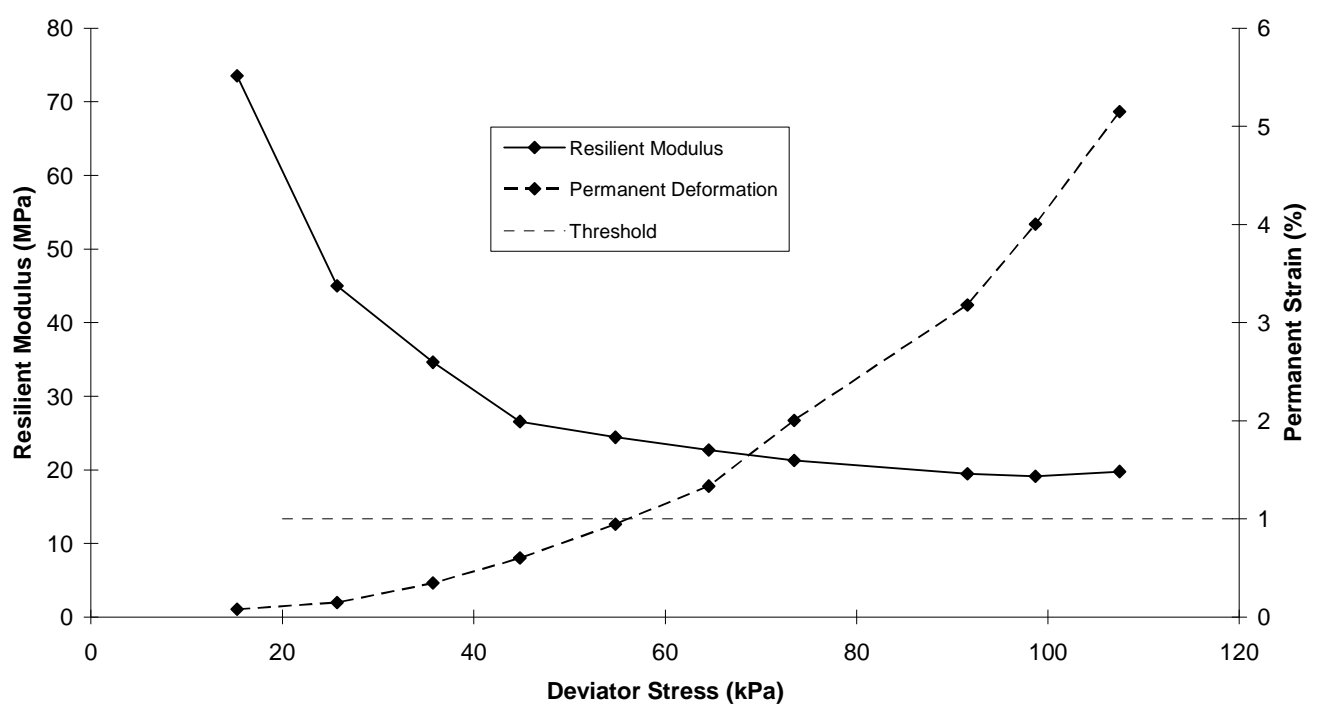




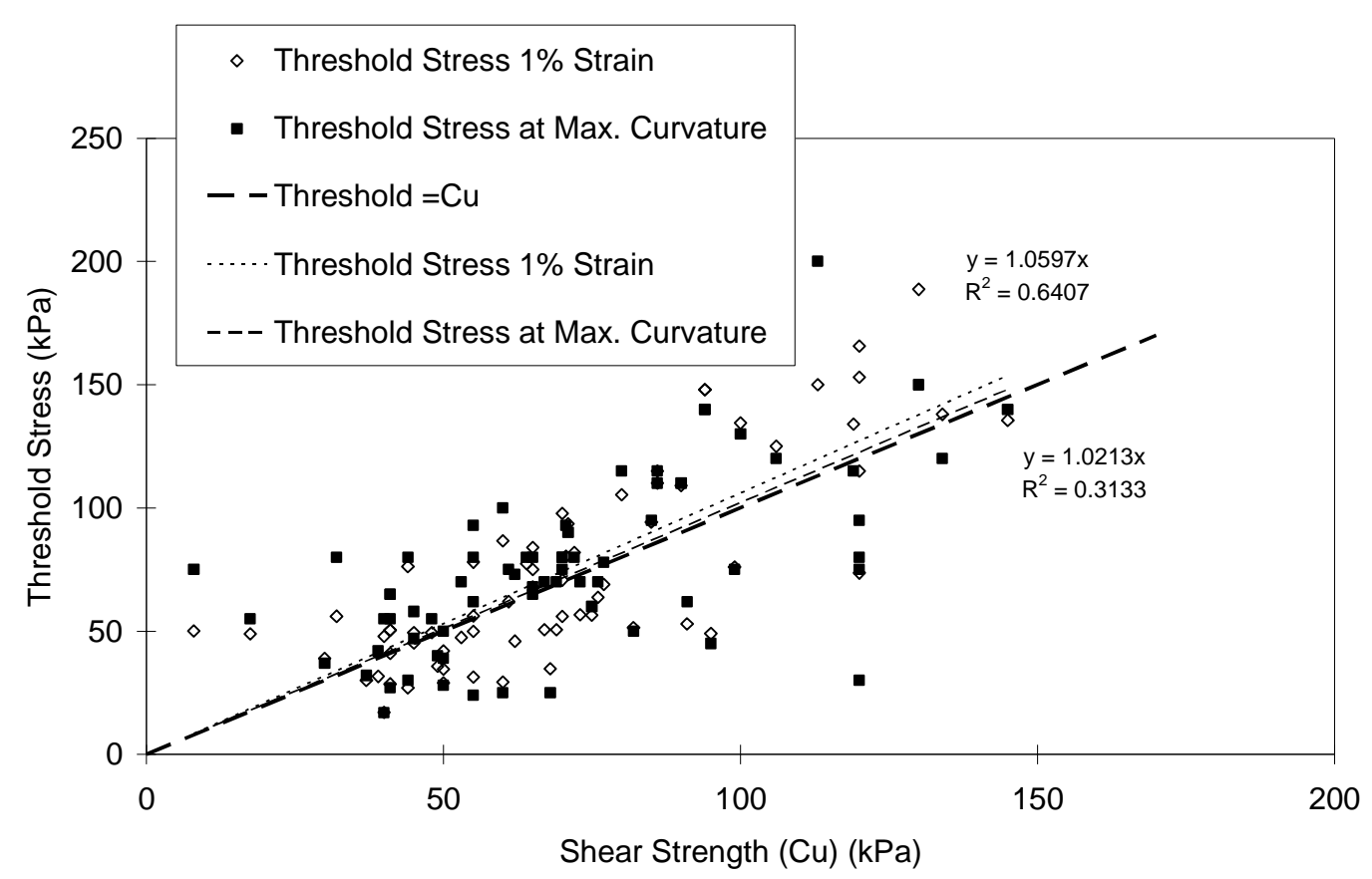

Figure 2. Relationship between Threshold Stress and Undrained Shear strength from Repeated Load Triaxial Tests, (Reproduced from 2). 


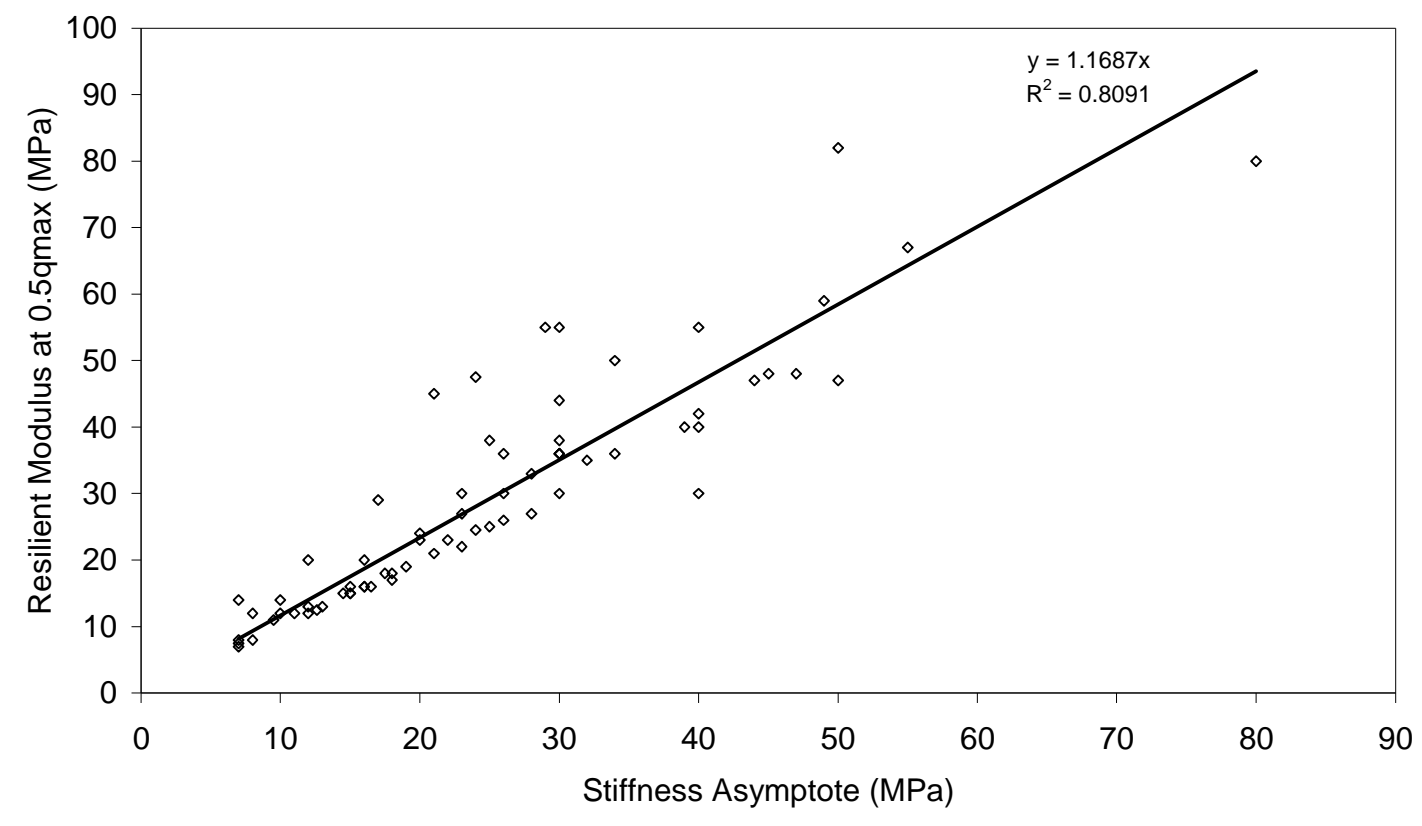

Figure 3. Relationship between Resilient Modulus at Threshold Stress and Asymptotic Resilient Modulus, (Reproduced from 2).

23

24

25

26

27

28

29

30

31

32

33

34

35

36

37

38

39

40

41

42

43

44

45

46

47

48

49

50

51

52 


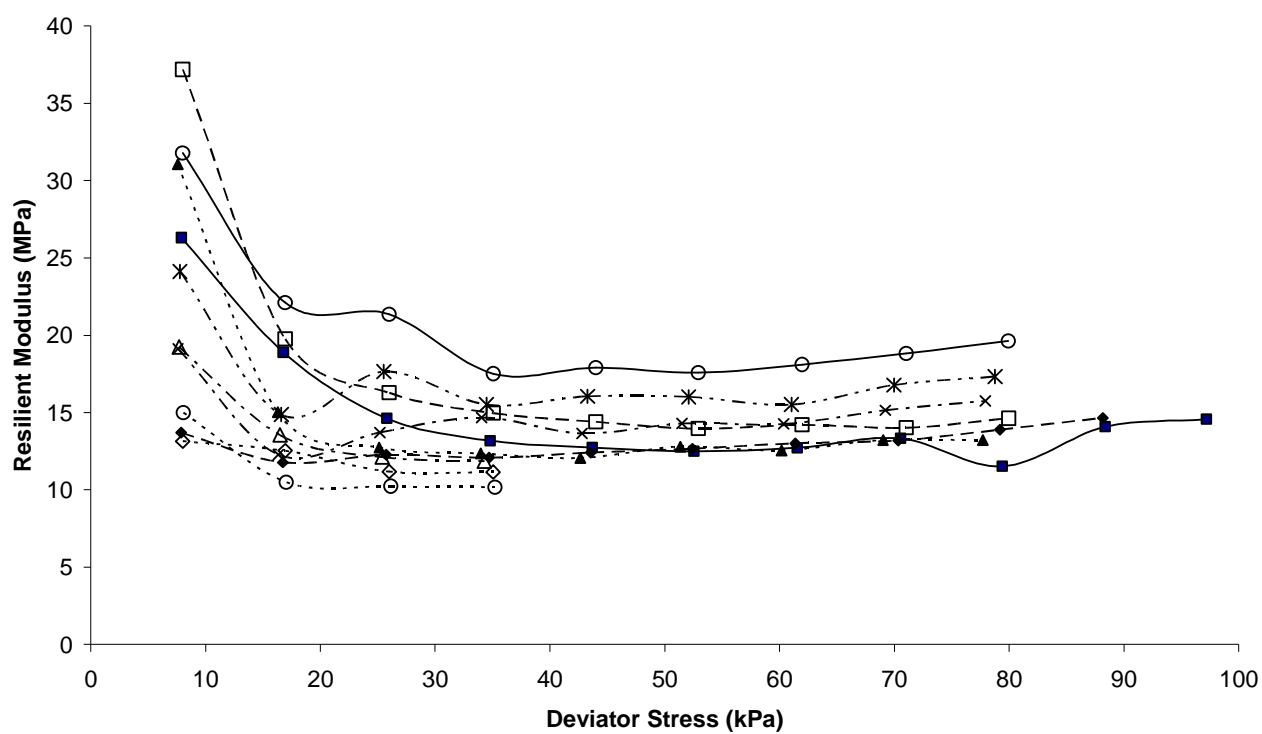

Figure 4. Typical Relationship between Resilient Modulus and Deviator Stress Tested Pseudo Statically in a Conventional Triaxial Cell, for Samples of Mercia Mudstone (MM). 
1

Figure 5. Typical Comparison of the Relationship between Resilient Modulus and Deviator Stress for both Pseudo Static and Cyclic Testing on Mercia Mudstone Samples.

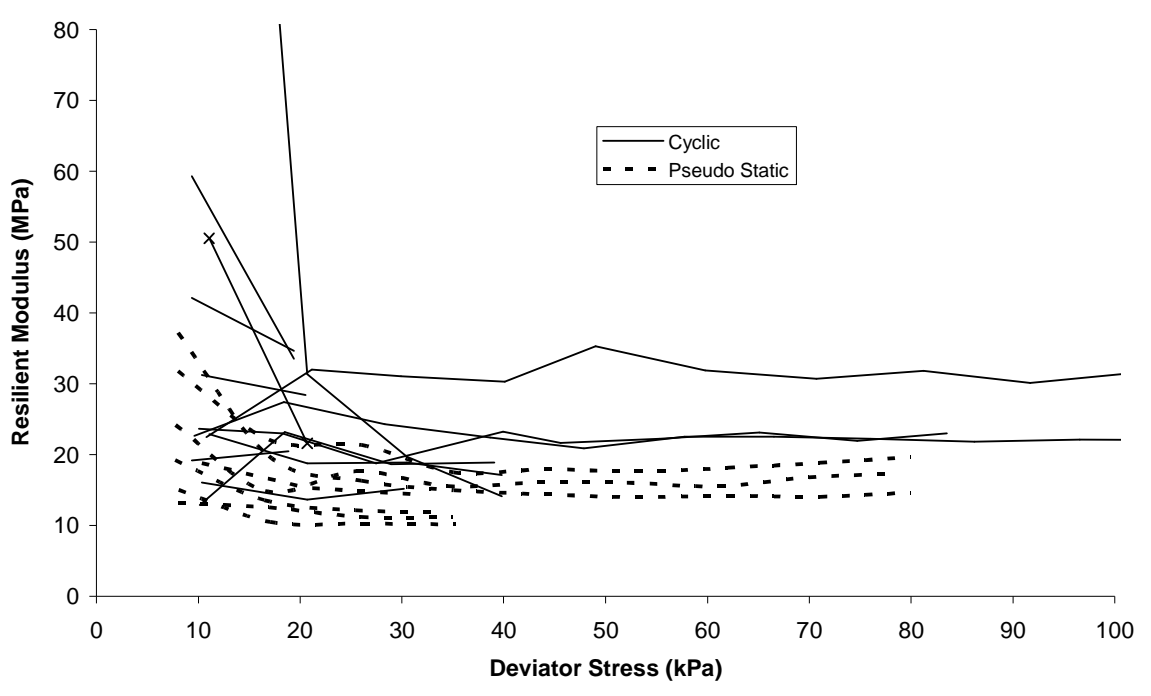




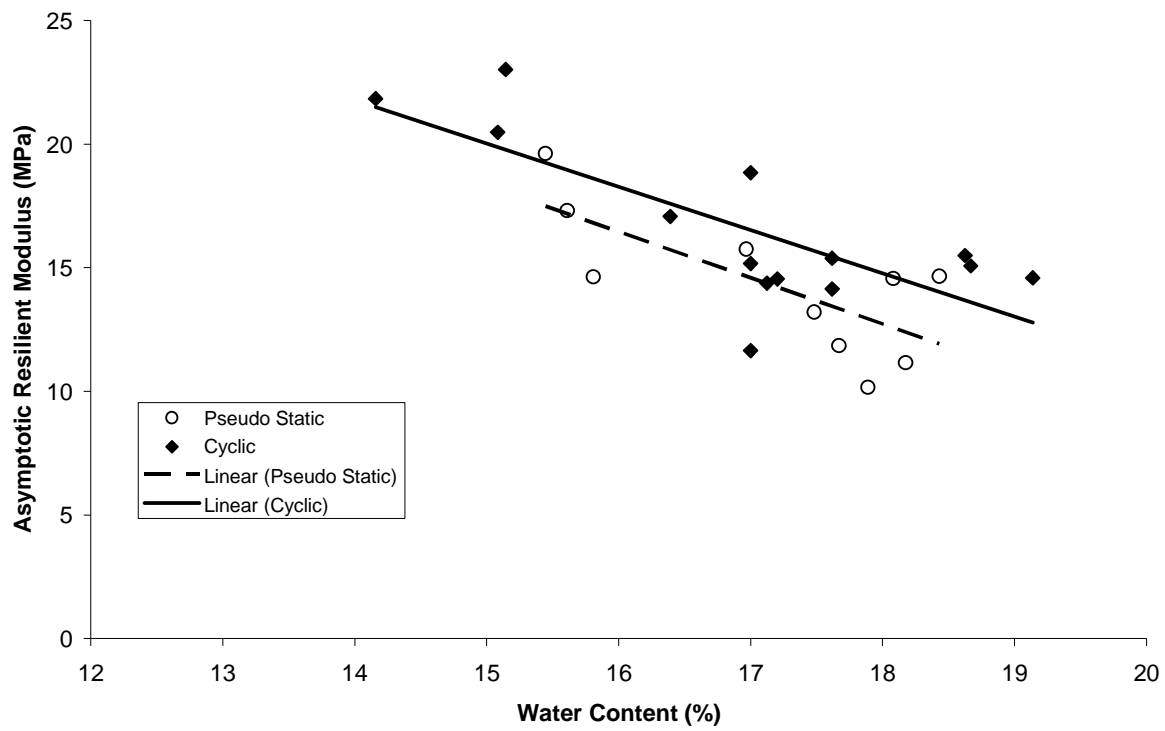

Figure 6. Typical Relationship Between Asymptotic Resilient Modulus and Water Content for Samples Tested using the Pseudo Static Testing Regime and Cyclic Triaxial Testing. 


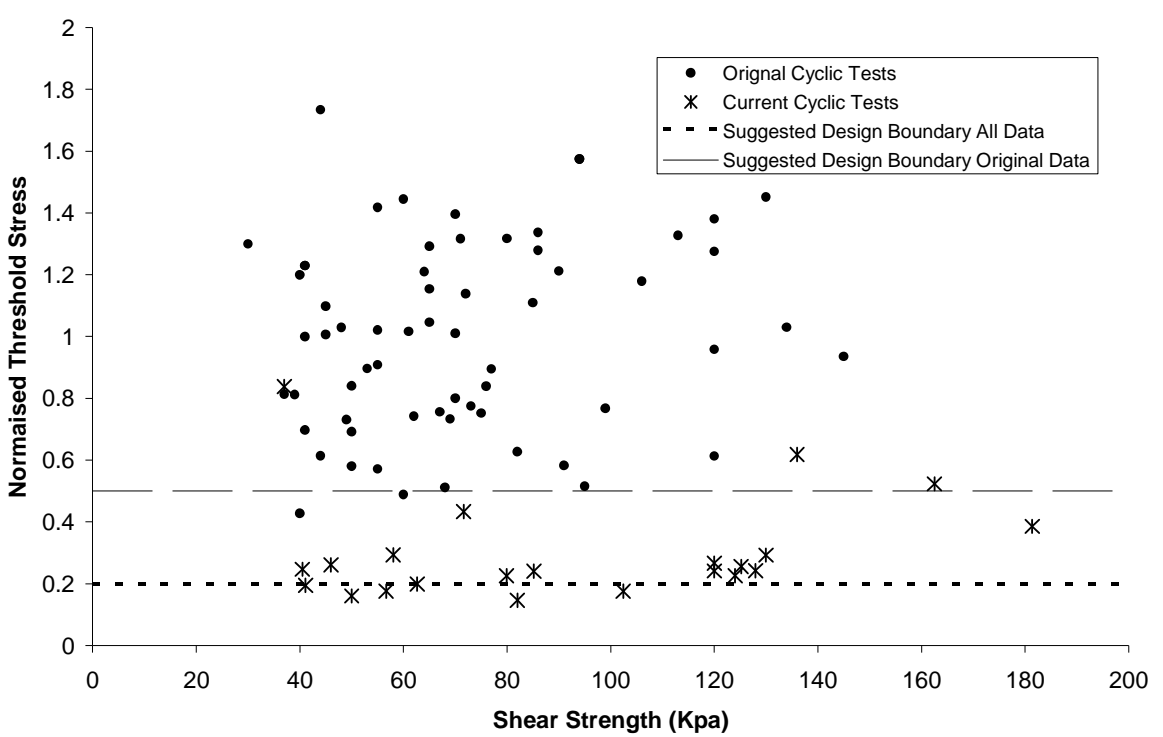

Shear Strength (Kpa)

Figure 7. Relationship between Normalized Threshold Stress (Deviator Stress at 1\% Strain / Undrained Shear Strength) and Undrained Shear Strength 